\title{
Desempenho físico-mecânico de compósitos à base de gesso reforçados com embalagens multicamadas trituradas
}

\author{
Physical-mechanical performance of reinforced \\ gypsum composites with crushed multi-layer \\ packaging
}

\author{
Luciana Silva Villela ${ }^{1}$, Eliziane Denize de Castro ${ }^{1}$, Laércio Mesquita Júnior ${ }^{1}$, \\ Maria Cecillia Ramos de Araújo Veloso ${ }^{1}$ Rafael Farinassi Mendes ${ }^{2}$, \\ Lourival Marin Mendes ${ }^{3}$, José Benedito Guimarães Júnior ${ }^{2}$
}

\footnotetext{
${ }^{1}$ Engenharia de Biomateriais - Departamento de Ciências Florestais - Universidade Federal de Lavras, CP. 3037, CEP: 37200-000, Lavras, MG, Brasil.

${ }^{2}$ Departamento de Engenharia - Universidade Federal de Lavras, CP. 3037, CEP: 37200-000, Lavras, MG, Brasil.

${ }^{3}$ Departamento de Engenharia Florestal - Universidade Federal de Lavras, CP. 3037, CEP: 37200-000, Lavras, MG, Brasil. e-mail: lucianavillela_3@hotmail.com, eliziane.castro@yahoo.com.br, laerciomjr@gmail.com, mariacraveloso@outlook. com,rafael.mendes@deg.ufla.br, jose.guimaraes@deg.ufla.br, lourival@dcf.ufla.br
}

\begin{abstract}
RESUMO
As embalagens multicamadas são utilizadas por um período de tempo bastante curto gerando um volume de descarte elevado. Por serem formadas por diferentes materiais devido suas diversas camadas, sua reciclagem é dificultada. Sendo assim, são importantes novas aplicações para essas embalagens pós-consumo, como por exemplo o seu reaproveitamento em compósitos. Neste contexto, o objetivo deste trabalho foi desenvolver e caracterizar compósitos à base de gesso reforçados com embalagens multicamadas trituradas. As proporções utilizadas para a incorporação dos reforços foram de $0 \%$, $7,5 \%, 15 \%, 22,5 \%$ e $30 \%$ em substituição ao gesso. Foram produzidos corpos de prova (três repetições por tratamento) para avaliação das propriedades de absorção de água, umidade, massa específica aparente, compressão e flexão estática, os quais foram confeccionados com dimensões de 40 x 40 x $160 \mathrm{~mm}$. Para o ensaio térmico, as dimensões foram de 200 × 200 x 20 $\mathrm{mm}$. Os reforços adicionados levaram a um aumento em umidade e absorção de água, enquanto que, para massa específica aparente, condutividade térmica, resistência à flexão, resistência à compressão e rigidez na compressão houve decréscimo. A incorporação de embalagens multicamadas em compósitos de gesso mostrou ser uma alternativa viável, visto que, além de aplicar a logística reversa reutilizando estas embalagens que muitas vezes são descartadas no meio ambiente de maneira inadequada, gerando diversos impactos, ainda melhorou a propriedade térmica dos compósitos e diminuiu a densidade destes. Ademais, todas as porcentagens atenderam a normatização para resistência à flexão, e para a resistência à compressão, apenas a substituição de $30 \%$ não atendeu a normativa.
\end{abstract}

Palavras-chave: Propriedades físicas e mecânicas; Condutividade térmica; Embalagens Cartonadas; Materiais Compósitos.

\begin{abstract}
The multilayer packages are used for a very short time generating a high discard volume. Because they are formed by different materials due to their several layers, their recycling is difficult. Therefore, new applications for these post-consumer packages are important, such as their reuse in composites. In this context, the objective of this work was to develop and characterize plaster based composites reinforced with crushed multilayer packages. The proportions used to incorporate reinforcements were $0 \%, 7.5 \%, 15 \%, 22.5 \%$ and $30 \%$, replacing gypsum. Test specimens (three replicates per treatment) were produced to evaluate the properties of water absorption, moisture, apparent specific mass, compression and static bending, which were made with dimensions of $40 \mathrm{x} 40 \mathrm{x} 160 \mathrm{~mm}$. For the thermal test, the dimensions were $200 \mathrm{x} 200 \mathrm{x}$ $20 \mathrm{~mm}$. The added reinforcements led to an increase in moisture and water absorption, whereas, for apparent specific mass,
\end{abstract}


flexural strength, compressive strength and stiffness in compression there was decrease. The incorporation of multilayer packages into plaster composites proved to be a viable alternative, since in addition to applying reverse logistics reusing these packages that are often discarded in the environment in an inadequate manner, generating several impacts, it also improved the thermal properties of the composites, their density decreased, all percentages complied with normalization for flexural strength, and for compression strength, only the $30 \%$ insertion did not meet the standards.

Keywords: Physical and mechanical properties; Thermal conductivity; Carton packaging; Composite materials.

\section{INTRODUÇÃO}

A busca pelo desenvolvimento de materiais inovadores e sustentáveis é cada vez mais crescente. Procura-se incorporar subprodutos de outras indústrias, buscando-se obter materiais mais favoráveis ao ambiente, mais econômicos, duráveis, resistentes e com elevada ductilidade [1]. Neste contexto, o gesso tem sido um assunto importante entre muitos pesquisadores devido a sua grande disponibilidade no ambiente mas principalmente pelo fato de que em comparação com a fabricação do cimento, que exige altas temperaturas para seu processo e libera grande quantidade de gás carbônico devido à combustão necessária para sua desidratação e calcinação, o gesso é um aglomerante menos agressivo ao meio ambiente [2].

Embora o gesso tenha propriedades atrativas para a construção civil como ausência de retração por secagem, ótimas propriedades térmicas e acústicas, resistência ao fogo, endurecimento rápido e excelente acabamento superficial, este material ainda apresenta uma série de limitações, como alta permeabilidade à água, natureza porosa, baixa resistência à compressão, baixa resistência à flexão e tração, sendo utilizado somente para ambientes internos [3].

Ao longo dos últimos anos, muitos estudos, nos quais foi utilizado o gesso como matriz para a produção de compósitos reforçados com partículas e fibras lignocelulósicas, fibras sintéticas e resíduos sólidos, foram publicados. Dentre estes, citam-se a incorporação na matriz de gesso fibras de palmeira [4], resíduos de madeira de demolição [5], cinzas de bagaço de cana [6], abacá [7], fibras de bananeira e papel kraft [8], fibras têxteis, acrílicas, de vidro, de basalto, de banana e de sisal [9], partículas de borracha de pneus reciclados [10], granulado de cortiça e fibras têxteis [11], fibras lignocelulósicas de bambu, coco e sisal [12], vermiculita e etileno acetato de vinila (EVA) [13], dentre outros. A utilização desses diferentes reforços não só abrange o conceito de sustentabilidade, como também contribuiu para o desenvolvimento de novos materiais, com melhores propriedades térmicas, acústicas, físicas e mecânicas.

Selamat et al. [14] em seu trabalho, incorporou diferentes porcentagens de fibras do tronco do dendezeiro na matriz de gesso a fim de verificar melhorias em suas propriedades. Os autores observaram acréscimo significativo da resistência mecânica com a inclusão de carga sendo constatado $20 \%$ como valor ideal de reforço na matriz. Ainda, suas amostras apresentaram melhorias na resistência ao fogo em comparação ao gesso puro indepedente da porcentagem de carga adicionada. Já Braiek et al. [4] fizeram inclusão de 0 a 20\% de fibra de palmeira na matriz de gesso e demonstraram que a condutividade térmica era reduzida gradativamente com o aumento de reforço inserido. Resultados como esses corroboram com a ideia de utilizer reforços em matrizes.

Um resíduo sólido que pode ser utilizado como reforço em compósitos são as embalagens multicamadas, também conhecidas como embalagens cartonadas, longa vida ou tetra pak ${ }^{\circledR}$, visto que elas são utilizadas por um período de tempo bastante curto, gerando um volume de descarte elevado. Por serem formadas por diferentes materiais como papel cartão, folha de alumínio e polietileno, sua reciclagem é dificultada. Dessa forma, fabricantes investem na logística reversa como forma de fazer com que o produto passe por uma reciclagem adequada que separe seus três constituintes dando-lhes finalidade. Porém, isso se torna dificultado tendo em vista a necessidade da coleta seletiva pelos consumidores e esta, no Brasil, ainda funciona de forma ineficiente na maioria das cidades. Assim, grande parte do volume de resíduo gerado não tem destinação correta, sendo descartado em aterros ou até mesmo à ceu aberto, o que traz problemas ao meio ambiente e danos a saúde pública. Tendo em vista esse cenário, surge a importância de determinar novas aplicações para essas embalagens pós-consumo, como, por exemplo, o seu reaproveitamento em compósitos.

Nesse contexto, objetivou-se, neste trabalho, avaliar as propriedades físicas, mecânicas e térmicas de material compósito à base de gesso reforçado com embalagens multicamadas trituradas, aplicando a logística reversa, reutilizando estes resíduos e buscando produzir novos materiais, com melhores propriedades, como leveza, melhor conforto térmico e maior resistência mecânica.

\section{MATERIAIS E MÉTODOS}

Foi utilizado como matriz para produção dos compósitos, gesso fino para fundição proveniente do polo gesseiro do Araripe, no estado de Pernambuco. Esse material apresenta como características massa específica aparente de $781 \mathrm{~kg} / \mathrm{m}^{3}$, e tempo de inicio e fim de pega de 9 e 22 minutos, respectivamente e módulo de finura de 0,85 . 
Como reforço utilizou-se as embalagens multicamadas, que foram obtidas em pontos de coletas destinados para reciclagem dessas embalagens pós-consumo. Elas foram abertas e lavadas com água corrente. Posteriormente, foram picotadas em dimensões de aproximadamente $10 \times 10 \mathrm{~mm}$ (Figura 1a) e trituradas em moinho de facas, com peneira de abertura de $0,42 \mathrm{~mm}$, passando a apresentar aspecto fibroso (Figura $1 \mathrm{~b}$ e $1 \mathrm{c}$ ). Foi determinado sua massa específica pelo método da proveta graduada, conforme descrito por Protásio et al [15]. Estas foram incorporadas nas proporções de 0\%, 7,5\%, 15\%, $22,5 \%$ e $30 \%$, em substituição ao volume de gesso.
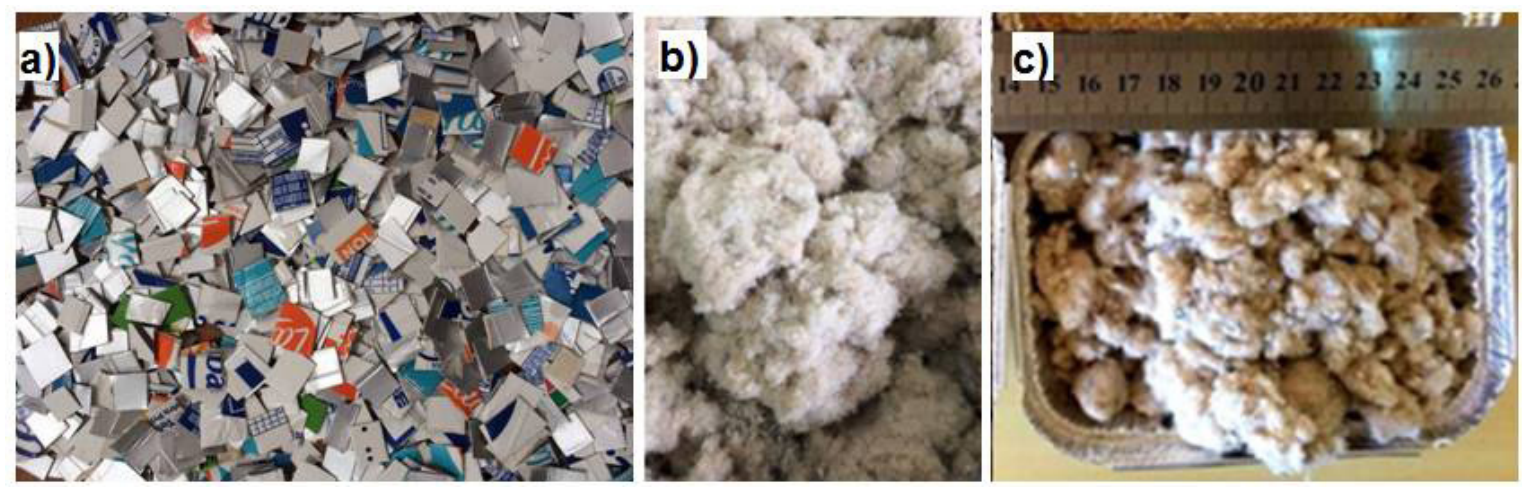

Figura 1: (a) Embalagens multicamadas picotadas. (b) e (c) Embalagens cartonadas trituradas.

A relação água/gesso foi determinada de acordo com a norma EN 13279-2 [16], seguindo o método de aspersão, pela massa de gesso que pode ser saturada quando são polvilhados em $100 \mathrm{~g}$ de água, o objetivo era encontrar uma trabalhabilidade ideal e uma resistência adequada sem incorporar aditivos. O traço foi determinado com base na massa unitária do gesso, sendo calculada conforme a NBR 12127 [17] e NBR 13207 [18].

$\mathrm{Na}$ avaliação das propriedades físico-mecânicas dos compósitos foram adotados os seguintes procedimentos para cada ensaio realizado:

Umidade na base seca: NBR 7190 [19].

Densidade aparente: NBR 45 [20].

Ensaio de absorção de água: NBR 14715-2 [21].

Resistência em flexão: EN 13279-2 [16].

Resistência em compressão: EN 13279-2 [16]

Os corpos de prova para os ensaios físicos e mecânicos foram confeccionados com o auxílio de uma forma feita de MDF, fabricada com fundo em madeira, de forma a garantir que as dimensões dos corpos de prova fossem de $40 \mathrm{x} 40 \mathrm{x}$ $160 \mathrm{~mm}$, conforme especificações da EN 13279-2 [16]. Para realizar o ensaio térmico, os corpos de provas foram feitos com ripas de madeira, de forma a garantir que as suas dimensões fossem de 20 x $20 \times 2 \mathrm{~cm}$. Para cada tratamento foram moldados três corpos de prova. Após o período de 24 horas, eles foram retirados dos moldes e colocados em local livre da ação de intempéries. Durante cinco dias eles foram virados diariamente, para garantir uma secagem uniforme e no sexto dia foram acondicionados em estufa com circulação forçada de ar, à temperatura de $40 \pm 4^{\circ} \mathrm{C}$, até atingirem a massa constante. No sexto dia realizou-se o ensaio de umidade e no sétimo dia, após ter sido seca em estufa realizou-se os ensaios de absorção de água, massa específica aparente, flexão, absorção de água e ensaio térmico.

Para determinar a umidade dos corpos de prova, as amostras, após o período de seis dias de cura foram pesadas, obtendo-se sua massa úmida. Posteriormente, elas foram armazenadas em estufa ventilada, à temperatura de $40 \pm 4^{\circ} \mathrm{C}$, até atingirem a massa constante. Decorrido esse tempo, elas foram novamente pesadas, determinando-se sua massa seca. A umidade na base seca foi determinada calculada através da equação 1 .

$\mathrm{U}(\%)=(\mathrm{Mu}-\mathrm{Ms}) / \mathrm{Mu}$

Em que,

U - umidade do corpo de prova na base seca (\%);

Mu- massa úmida do corpo de prova (g); 
Ms- massa seca do corpo de prova (g).

Para o ensaio de absorção de água obteve-se a massa inicial dos corpos de prova após o período de cura e com peso constante. Para auferir a sua massa final, estes foram imersos em água por 2 horas e, após esse tempo, removeu-se o excesso de água com o auxílio de um pano seco para possibilitar a pesagem de sua massa final saturada. A absorção de água foi determinada pela equação 2 .

$\mathrm{AA} 2 \mathrm{~h}=((\mathrm{Mf}-\mathrm{Mi}) / \mathrm{Mi}) \times 100$

Em que,

AA2h - absorção de água após 2 horas de imersão em água (\%);

Mf- massa final do corpo de prova (g);

Mi - massa inicial do corpo de prova $(\mathrm{g})$.

A massa específica aparente foi determinada pela equação 3. Os corpos de prova, já secos, foram pesados em uma balança eletrônica de precisão $0,01 \mathrm{~g}$ e, para se obter o volume, foi tomada a média de suas arestas utilizando um paquímetro.

(m/ x.y.z) x 100

Em que,

$D$ é a densidade aparente, em quilogramas por metro cúbico;

$m$ é a massa do corpo de prova, em gramas;

$x, y$ e z é o volume do corpo de prova, em milímetro cúbico;

A resistência à flexão foi definida de acordo com o método da EN 13279-2 [16]. Neste ensaio um carregamento central é aplicado ao corpo de prova prismático de 40 x 40 x $160 \mathrm{~mm}$, que é colocado sobre dois apoios afastados $100 \mathrm{~mm}$ entre si.

A resistência à compressão foi determinada com as metades dos corpos de prova utilizados no ensaio de resistência à flexão, conforme a mesma norma. Avaliou-se a rigidez na compressão dos compósitos, obtendo o módulo de elasticidade.

O ensaio para análise do isolamento térmico consistiu em utilizar duas câmaras sobrepostas de painéis de madeira reconstituída (Figura 2a) vedadas interiormente com isopor de $20 \mathrm{~mm}$ de espessura e, mais internamente, por uma manta térmica, para que não houvesse interferência da temperatura ambiente na temperatura do interior das câmaras. Para o aquecimento do equipamento utilizou-se uma lâmpada incandescente com temperatura controlável. Na Figura $2 b$ pode-se observar esquema do equipamento utilizado para realização do ensaio de isolamento térmico. 


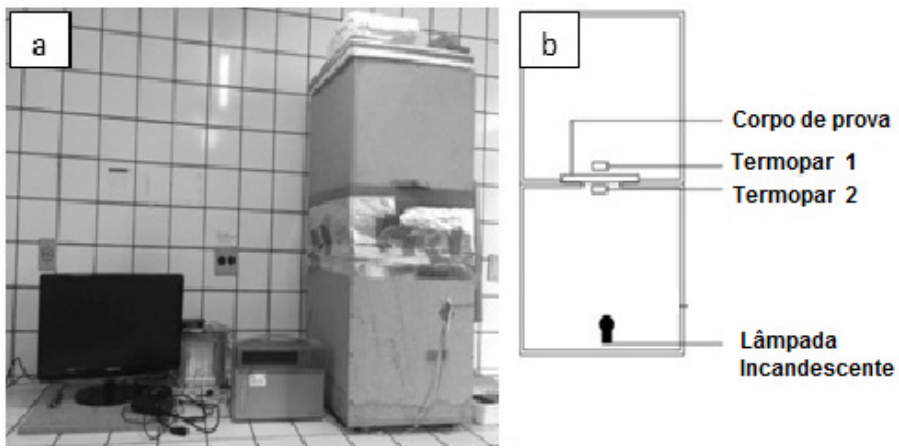

Figura 2: Equipamento utilizado para análise do isolamento térmico

Neste método de ensaio, o isolamento é obtido quando a estabilidade é atingida, as temperaturas são registradas por sensores através de um equipamento Data Collector, modelo IM DC 100-01E. Os compósitos foram posicionados no equipamento e o ensaio realizado simulando a exposição do material à temperatura em torno de $50^{\circ} \mathrm{C}$. A razão de aquecimento foi de $1{ }^{\circ} \mathrm{C} /$ min. e o ciclo de ensaio para cada tratamento de 180 minutos. A condutividade térmica foi calculada considerando a radiação emitida pela fonte de calor, obtida com o auxílio de um aparelho medidor de radiação, multiplicada pela espessura do corpo de prova, e dividindo pela variação de temperatura, calculada a partir das trinta últimas medições registradas pelos termopares, na base e no topo dos corpos de prova (Equação 4).

$\mathrm{C}=($ w.e $) / \Delta \mathrm{T}$

Em que,

$\mathrm{C}$ - condutividade térmica $\left(\mathrm{W} / \mathrm{m}^{\circ} \mathrm{K}\right)$;

W - voltagem da lâmpada (W);

e - espessura do corpo de prova $(\mathrm{m})$;

$\Delta \mathrm{T}$ - variação de temperatura entre as faces da amostra $\left({ }^{\circ} \mathrm{K}\right)$.

A microscopia eletrônica de varredura (MEV) foi realizada para caracterizar a superfície de ruptura dos corpos de prova após os ensaios mecânicos na região de fratura, com o objetivo de analisar a interface entre a matriz de gesso e o reforço, a fim de verificar se o reforço foi arrancado ou rompido e ainda, a ocorrência de espaços vazios entre reforço e matriz. As amostras passaram, inicialmente, por dois banhos de ouro, sendo, posteriormente, avaliadas mediante a utilização de um microscópio eletrônico de varredura da marca Zeiss Modelo DSM 940ª Microscópio LEO EVO 40 XVP (Carl Zeiss) com sistema de microanálise de raios X da Bruker (Quantax EDS) e criosystem (Gatan).

Para a análise dos dados utilizou-se o delineamento inteiramente casualizado com três repetições para cada tratamento. Foi efetuada análise de variância e regressão linear, com 5\% de significância.

\section{RESULTADOS E DISCUSSÃO}

A massa específica aparente das embalagens multicamadas trituradas foi $0,214 \pm 0,026 \mathrm{~g} / \mathrm{cm}^{3}$. As relações água/gesso encontradas foram de 0,60 para o controle $(0 \%)$ e com 7,5\% de substituição das embalagens multicamadas trituradas, 0,75 para a modificação de $15 \%$ e 0,80 para as demais incorporações $(22,5 \%$ e $30 \%)$. O aumento da razão água e gesso a partir da substituição deste pelo material reciclado é ocasionado pela perda de trabalhabilidade no compósito, visto que, cerca de $75 \%$ dessas embalagens são formadas por camadas de papel, o qual apresenta natureza higroscópica .

A quantidade de água utilizada tem influência direta na resistência mecânica e na rigidez do corpo de prova de gesso que depende do encadeamento dos cristais di-hidratados e da porosidade resultante [22]. A presença de porosidade na microestrutura de blocos rígidos de gesso está relacionada, em geral, com a quantidade de água, uma vez que quanto maior a quantidade de água, maior será a quantidade de vazios (poros) deixados pela água evaporada na secagem. O aumento dos poros propicia um decréscimo as propriedades mecânicas, como resistência à compressão e flexão, entretanto, diminui a condutividade térmica do material, já que o ar que fica nos poros tem baixa condutividade térmica $(0,023 \mathrm{~W} / \mathrm{m} . \mathrm{K})$, constituindo um elemento muito resistente à passagem de calor.

Oliveira et al. [13] incorporaram vermiculita e etileno acetato de vinila (EVA) em compósitos de gesso, estudando diferentes relações água/gesso $(\mathrm{a} / \mathrm{g}), 0,80 ; 0,90$ e 1,00, concluíndo que quanto maior foi a relação a/g menores foram as 
resistências. Os valores encontrados para resistência à compressão e massa específica dos compósitos diminuíram mais com o aumento da relação a/g do que com o aumento do percentual de adição dos reforços.

Serna et al. [10] incorporaram na matriz de gesso diferentes porcentagens de partículas de borracha de pneu, estudando diferentes razões de água e gesso $(0,6 ; 0,7$ e 0,8$)$, concluindo que a adição de partículas de borracha levou a uma diminuição nas propriedades mecânica dos compósitos, porém, as variações na relação água/gesso foram mais relevantes, em termos de propriedades mecânicas, do que a incorporações de partículas de borracha.

Na Figura 3a, 3b e 3c estão apresentados os valores de umidade, massa específica aparente e absorção de água, respectivamente, para os compósitos à base de gesso reforçados com embalagens multicamadas trituradas.

a)

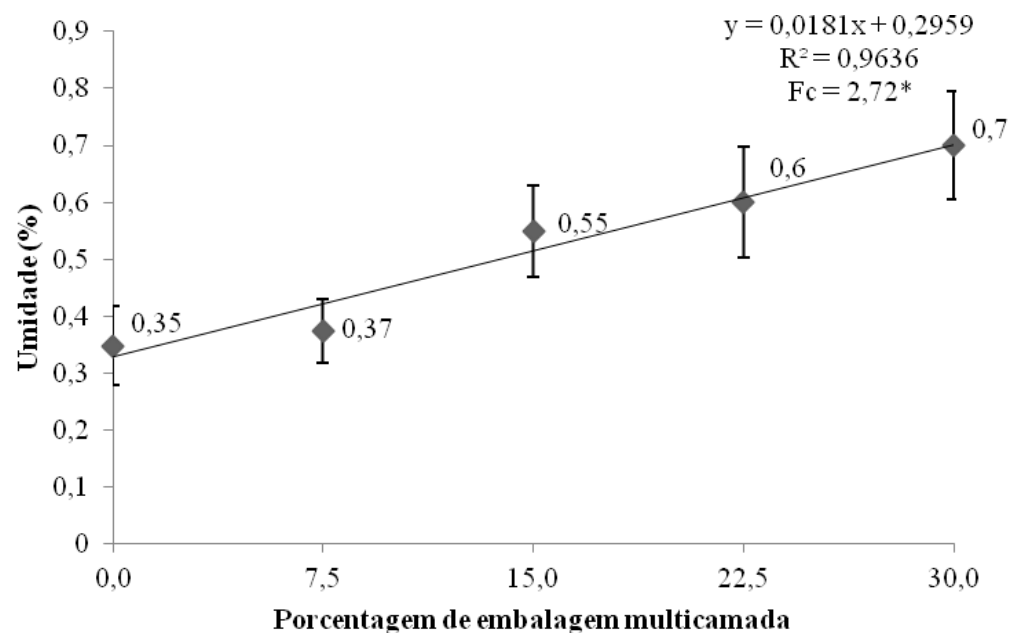

b)

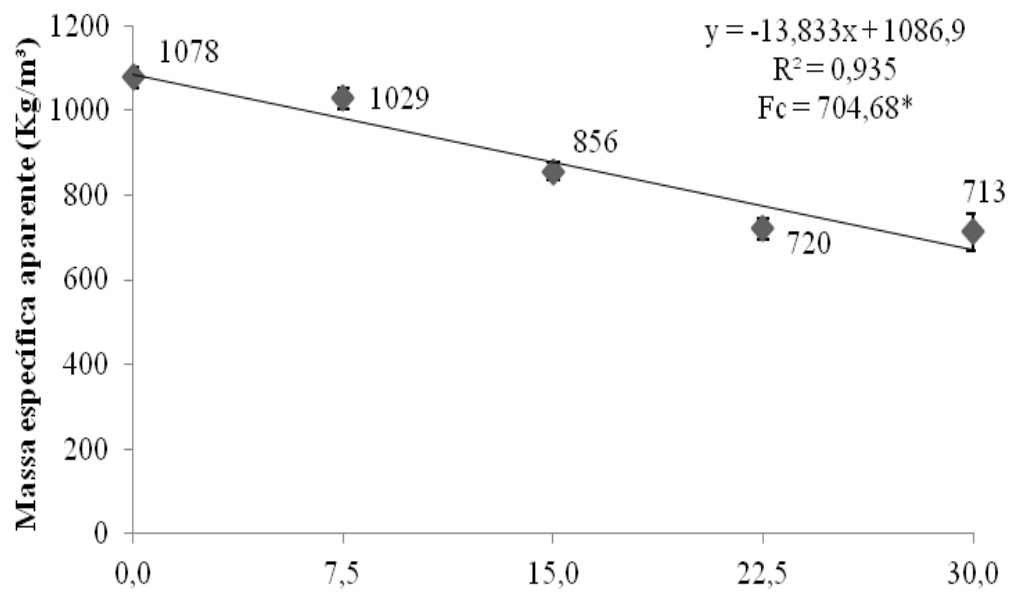

Porcentagem de embalagem multicamada

c)

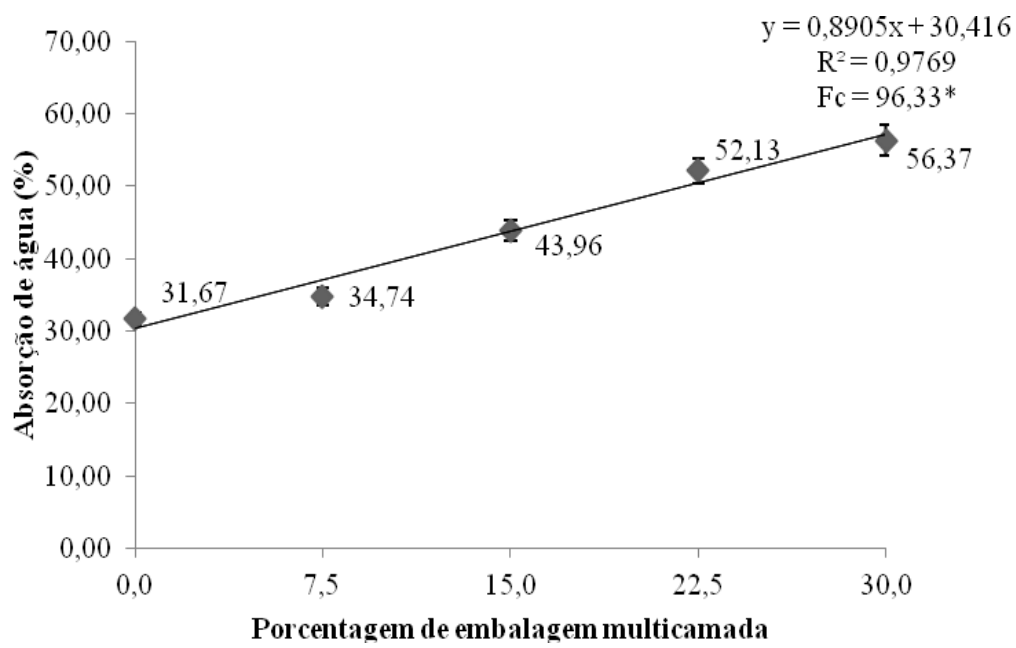

FIGURA 3: (a) Umidade para os compósitos. (b) massa específica aparente para os compósitos. (c) absorçao de água após duas horas para os compósitos. $\mathrm{R}^{2}=$ Coeficiente de determinação. * Nível de significância de 5\%. 
Para a umidade, os resultados na Figura 3a mostram que o aumento da porcentagem de reforços ocasionou um aumento na umidade do compósito, visto que, cerca de $75 \%$ dessas embalagens são formadas por camadas de papel, o qual apresenta natureza higroscópica [23]. Os valores de umidade encontrados variaram de $0,34 \%$ a $0,86 \%$. Observa-se que a umidade não aumentou mais de $2 \%$, o que, segundo Chinta et al. [24] pode ser considerado como controlado.

Chinta et al. [24] ao estudarem compósitos de gesso reforçados com fibras vegetais (coco, juta, lã, algodão e banana), observaram que à medida que se aumentava a porcentagem de fibras, a umidade aumentava gradualmente. Os autores encontraram valores de umidade entre $0,48 \%$ a $1,46 \%$.

Para a massa específica aparente, os resultados na Figura $2 \mathrm{~b}$ mostram que, em geral, o aumento da porcentagem de reforços ocasiona redução na massa específica aparente da matriz de gesso. A massa específica aparente dos compósitos variou de 713,44 a $1.077,88 \mathrm{~kg} / \mathrm{m}^{3}$ e o modelo de maior valor apresentado foi o traço de referência. Deve-se notar que essa diminuição ocorre uma vez que a massa específica aparente do gesso é maior do que a dos reforços que foram incorporados e pelo fato da relação água/gesso ser maior com o aumento dos níveis de incorporação dos reforços, visto que esse aumento produz uma matriz mais porosa e menos densa.

Rivero et al. [25] incorporaram borracha na matriz de gesso, encontrando, para a massa específica aparente, valores entre 880 e $1.003 \mathrm{~kg} / \mathrm{m}^{3}$, sendo constatada também diminuição na massa específica aparente, à medida que se incorporavam partículas de borracha.

Morales et al. [5] encontraram valores para a massa específica aparente entre 602 e $1.300 \mathrm{~kg} / \mathrm{m}^{3}$, quando incorporados resíduos de madeira de demolição em compósitos à base de gesso, sendo que o aumento da porcentagem de aditivos ocasionava uma redução na densidade dos compósitos.

Para a absorção de água, os resultados apontam na Figura 1c que o aumento da porcentagem de reforços ocasionou um aumento na absorção de água, variando de $31,67 \%$ à $56,37 \%$, esse aumento pode ter sido ocasionado devido ao caráter hidrofílico do reforço, devido também ao fato da relação água/gesso ser maior com o aumento dos níveis de incorporação dos reforços, sendo que esse aumento produz uma matriz mais porosa, absorvendo mais água.

Haselein et al. [26] confeccionaram chapas aglomeradas, utilizando gesso como material cimentante, papel reciclável dissociado (jornal e offset) e partículas de madeira de pinus como reforços. Ao avaliarem a absorção de água, encontraram, para a referência, valor médio de $28,73 \%$, próximo ao encontrado neste estudo para os compósitos sem incorporação de reforços $(31,67 \%)$.

Na Figura 4a, 4b e 4c estão apresentados os valores de resistência à flexão, resistência à compressão e o módulo de elasticidade na compressão (MOE), respectivamente, para os compósitos à base de gesso reforçados com embalagens multicamadas trituradas.

a)

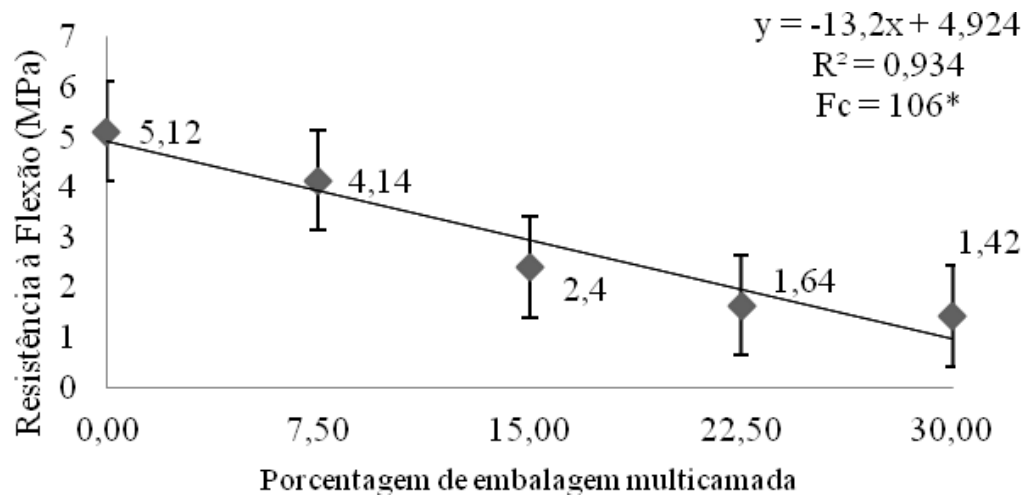

b)

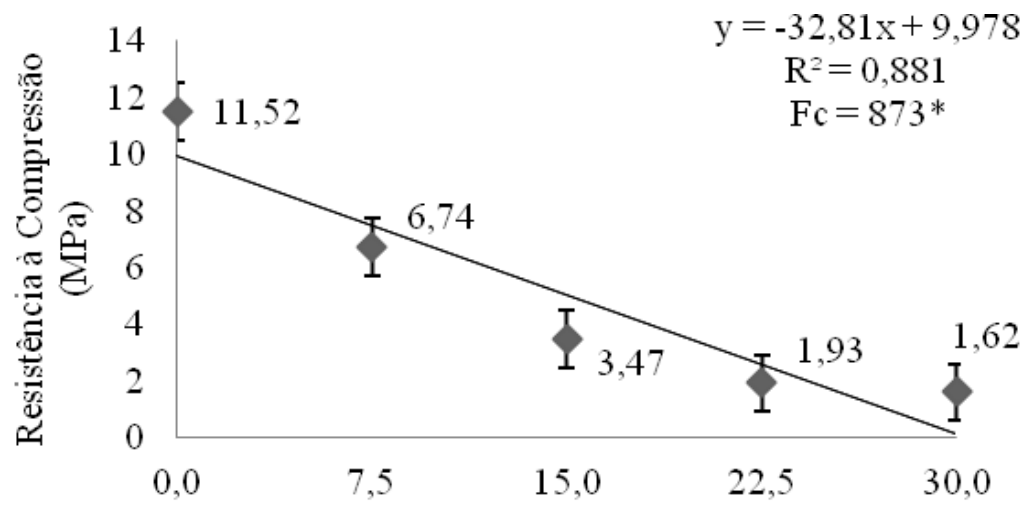

Porcentagem de embalagem multicamada 
c)

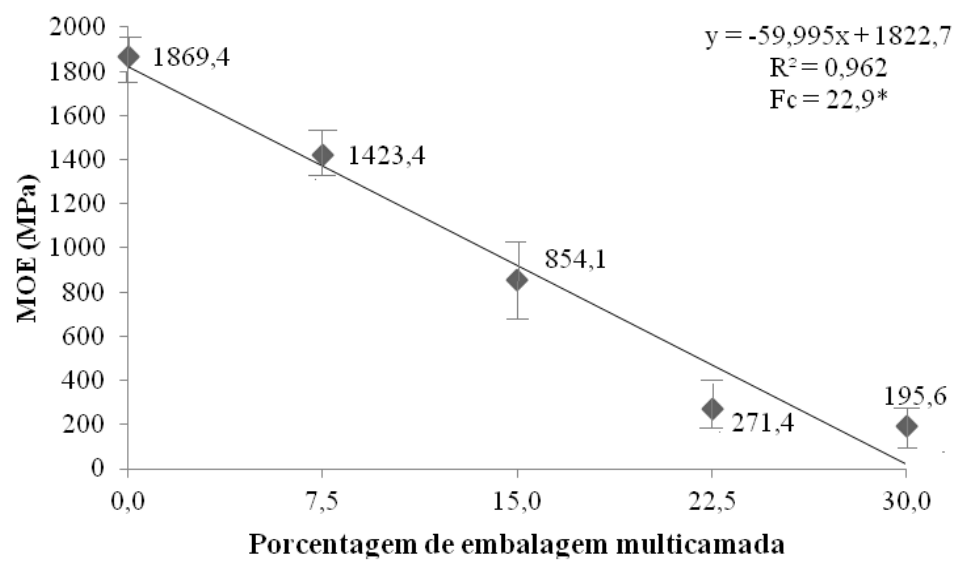

Figura 4: (a) Resistência à flexão dos compósitos. (b) Resistência à compressão dos compósitos. (c) módulo de elasticidade na compressão dos compósitos $\mathrm{R}^{2}=$ Coeficiente de determinação. * Nível de significância de $5 \%$.

Os resultados para resistência à flexão dos compósitos (Figura 3a) mostram que aqueles sem adição de reforços apresentaram maior resistência à flexão, a qual diminui progressivamente com o aumento da porcentagem dos reforços. Esta diminuição, provavelmente, ocorreu devido à densidade das embalagens multicamadas ser baixa e, segundo Markwardt $\mathrm{e}$ Wilson [27] ser altamente correlata com a resistência mecânica. Contudo, todos os tratamentos atendem ao valor mínimo exigido pela norma EN 13279-2 [16], que é de 1MPa.

Os valores de resistência à flexão dos compósitos variaram de 1,42 a 5,12 MPa. Os valores de referência, ou seja, compósitos sem adição de reforços, apresentaram valores de resistência à flexão média de $5,12 \mathrm{MPa}$, próximo ao encontrado por Nindiyasari et al. [28], Rivero, et al. [25] e Serna et al. [10], que encontraram 5,65; 5,11 e 5,45 Mpa, respectivamente.

Silva et al. [9] incorporaram à matriz de gesso fibras naturais e fibras sintéticas, encontrando valores de resistência à flexão média entre 2,40 a 5,10 MPa, semelhantes aos encontrados neste estudo. Os autores concluíram que as misturas com fibras de vidro e com fibras de basalto apresentaram os melhores resultados de resistência à flexão. Estes também relataram que mesmo as fibras dotadas de piores características mecânicas conferiram ao compósito um comportamento mais dúctil, quando comparadas à mistura sem fibras.

Com relação a resistência à compressão dos compósitos (Figura 3b), os resultados variaram de 1,62 a 11,62 MPa, tendo os compósitos sem adição de reforços o maior valor, 11,62 MPa. Morales et al. [5] incorporaram resíduos de madeira de demolição em compósitos a base de gesso, relatando que os valores médios da resistência mecânica à compressão dos compósitos caem com o aumento do percentual dos resíduos de madeira adicionados. Eles encontraram valores para a resistência à compressão variando entre 2,13 a 8,81 MPa.

A norma EN 13279-2 [16], define como valor mínimo de resistência à compressão $2 \mathrm{MPa}$. Substituindo os valores normatizados na equação de regressão, observou-se que para que seja atingida a resistência mínima prescrita, o valor máximo de inserção de embalagens multicamadas nos compósitos é de 24,3\%.

Para o módulo de elasticidade, os resultados na Figura 3c mostram que o aumento da porcentagem de reforços levou a uma diminuição do módulo de elasticidade dos compósitos, podendo ter ocorrido devido as embalagens multicamadas apresentarem baixo módulo de elasticidade, o que contribui para trabalharem no estágio pós-fissurado com grande absorção de energia e resistência à esforços dinâmicos. madas.

A Figura 5 apresenta os valores de condutividade térmica para os compósitos reforçados com embalagens multica- 


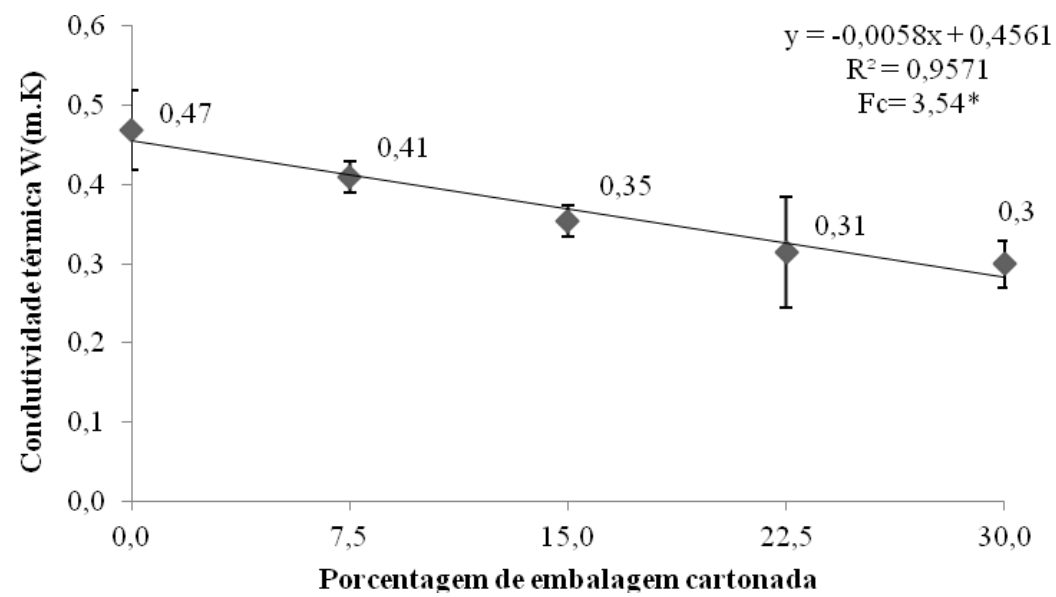

Figura 5: Condutividade térmica dos compósitos. $\mathrm{R}^{2}=$ Coeficiente de determinação. * Nível de significância de 5\%.

Nota-se que o aumento na porcentagem dos reforços diminuiu a condutividade térmica do compósito, proporcionando, assim, um material com maior isolamento térmico.

Um fator que pode contribuir para a ocorrência desta tendência é que a diminuição da condutividade térmica está ligada a uma queda na massa específica aparente da mistura, ou seja, quanto maior a porcentagem dos reforços, menor foi a massa específica dos compósitos e maior foi o isolamento térmico. Isso porque há ocorrência de maiores espaços vazios que são ocupados por ar, o qual apresenta baixo valor de condutibilidade térmica [29].

Braiek et al. [4] estudaram as propriedades termofísicas de compósitos gesso/fibras de palmeira, variando o teor de material lignocelulósicos de 0 a $20 \%$, encontrando, para a condutividade térmica do gesso puro, média de $0,452 \mathrm{~W} / \mathrm{m}$.K, valor próximo ao encontrado neste estudo $(0,469 \mathrm{~W} / \mathrm{m} . \mathrm{K})$.

As Figuras $6 \mathrm{a}$ e $6 \mathrm{~b}$ apresentam as micrografias de microscopia eletrônica de varredura (MEV) feitas nos compósitos sem incorporações de reforços (referência) e incorporados com embalagens multicamadas, respectivamente, sendo as amostras analisadas obtidas após o ensaio de flexão (fratura).
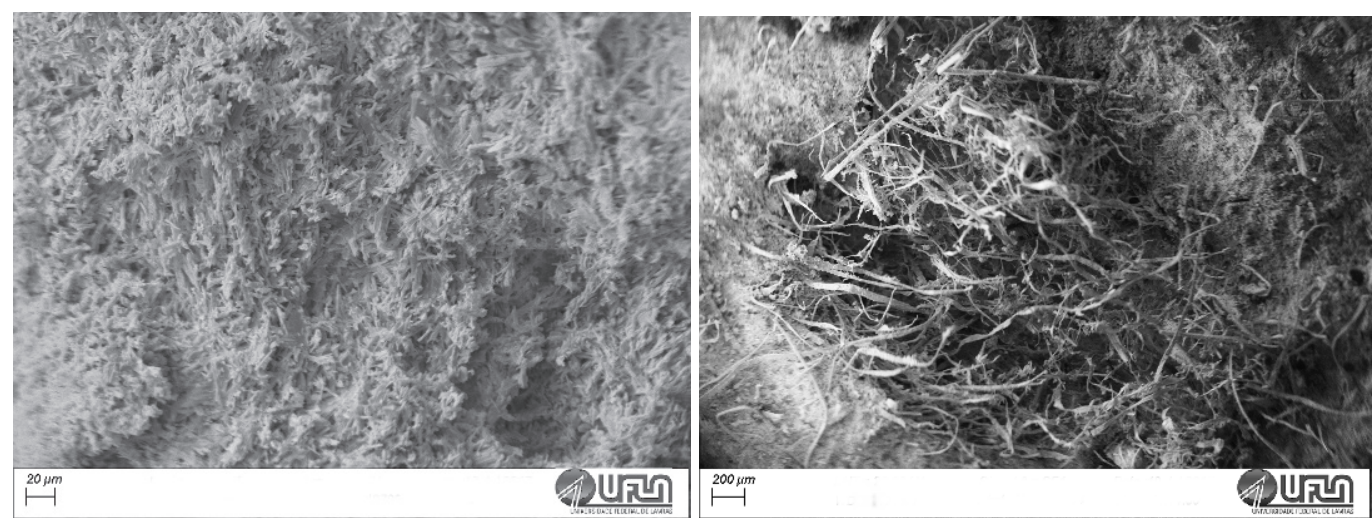

Figura 6: (a) micrografia de microscopia eletrônica de varredura (MEV) feita no compósito sem incorporações de reforços $(0 \%)$. (b) micrografia de microscopia eletrônica de varredura (MEV) feita no compósito com embalagens multicamadas $(30 \%)$.

As micrografias das amostras dos compósitos ajudam a explicar alguns dos resultados obtidos. Na Figura 6a, compósito referência, podem ser verificados cristais de gipsita alongados, prismáticos e em formato de agulhas, corroborando o relato de Gmouh et al. [30], que estudaram mudanças na microestrutura de gesso avaliando as potencialidades de reutilização dos resíduos de gesso que já foram empregados em obras de construção civil.

Nos compósitos produzidos com embalagens multicamadas (Figura 6b) ocorreu um agrupamento entre as fibras celulósicas, não se dispersando homogeneamente na matriz de gesso. Isso pode ter levado à redução das propriedades mecânicas. Mesquita et al. [31] trabalhando com compósito com inserção de fibras de sisal como reforço, observaram o mesmo comportamento de aglutinação das fibras em imagens de microscopia eletrônica de varredura, concluindo que esse 
fenômeno teria levado à redução da resistência e rigidez dos compósitos.

Esse agrupamento das fibras celulósicas presentes nas embalagens multicamadas dificultou a interação entre essa (reforço) e a matriz de gesso, e quando a interação entre a matriz e o reforço em materiais compósitos não ocorre de maneira desejada, ocorre o aparecimento de espaços vazios, diminuindo as principais propriedades dos materiais.

\section{CONCLUSÕES}

Os reforços adicionados aos compósitos resultaram em um produto final mais leve, a umidade e absorção de água aumentaram com incorporações dos reforços, já a condutividade térmica, resistência à flexão e resistência à compressão diminuíram.

Sendo assim, a incorporação de embalagens multicamadas em compósitos de gesso mostrou ser uma alternativa viável, visto que, além de aplicar a logística reversa reutilizando estas embalagens que muitas vezes são descartadas no meio ambiente de maneira inadequada, gerando diversos impactos ambientais, ainda melhorou a propriedade térmica dos compósitos, diminuiu a densidade destes, todas as porcentagens atenderam a normatização para resistência à flexão, e para a resistência à compressão, apenas a inserção de $30 \%$ não atendeu a normativa.

O aumento do reforço diminuiu a massa específica dos compósitos, propriedade atrativa para a construção civil, visto que materiais mais leves reduzem os esforços nas vigas, pilares e fundações. O aumento dos reforços utilizados também melhorou o comportamento térmico dos compósitos, mostrando uma oportunidade promissora para a utilização em vários produtos à base de gesso como por exemplo em placas de gesso para vedação ou forro, garantindo maior conforto térmico para a edificação.

\section{AGRADECIMENTOS}

À Universidade Federal de Lavras, CAPES, CNPq e a FAPEMIG, que colaboraram para a realização deste estudo.

\section{BIBLIOGRAFIA}

[1] VILA-CHÃ, N. "Estudo de um material compósito à base de gesso e cortiça", Dissertação de M.Sc., Universidade do Minho, Braga, 2012.

[2] PINTO, N. A., FIORITI, C. F., BERNABEU, J. P. et al. "Avaliação de matriz de gesso com incorporação de borracha de pneus para utilização na construção civil”, Revista Tecnológica, v. 25, n. 1, pp. 103-117, 2016.

[3] SOPHIA, M., SAKTHIESWARAN, N., BABU G.O., "Gypsum as a Construction Material- A Review of Recent Developments”, International Journal for Innovative Research in Science \& Technology, v. 2, n. 12, pp. 1-9, 2016.

[4] BRAIEK, A., KARKRI, M., ADILI, A. et al. "Estimation of the thermos physical properties of date palm fibers/gypsum composite for use as insulating materials in building", Energy and Buildings, v. 140, pp. 268-279, 2017.

[5] MORALES-CONDE, M. J., RODRÍGUEZ-LIÑÁN, C., PEDREÑO-ROJAS, M. A. "Physical and mechanical properties of wood-gypsum composites from demolition material in rehabilitation works", Construction and Building Materials, v. 114, pp. 6-14, 2016.

[6] MEDINA ALVARADO, R., BURNEO VALDIVIESO, X., HERNÁNDEZ-OLIVARES, F. et al. "Reuse of organic waste type in the development of ecoefficient and sustainable composites", In: Anais do $2^{\circ}$ Congresso Internacional de Construcción Sostenible y Soluciones Ecoeficientes, pp. 297-309, Universidad de Sevilla, 2015.

[7] IUCOLANO, F., CAPUTO, D., LEBOFFE, F. et al. "Mechanical behavior of plaster reinforced with abaca fibers", Construction and Building Materials, v. 99, pp. 184-191, nov. 2015.

[8] NORONHA, L. L. "Elementos construtivos e de proteção térmica à base de gesso e resíduos agroindustriais”, Dissertação de M.Sc., Universidade Federal de Paraíba, João Pessoa, 2014.

[9] SILVA, L. M. C. C., CAMÕES, A., VASCONCELOS, G. "Material compósito à base de gesso reforçado com fibras: caracterização mecânica”, Universidade do Minho, n. 49, pp. 5-14, mai. 2014.

[10] SERNA, A., DEL RIO, M., PALOMO, J. G. et al., "Improvement of gypsum plaster strain capacity by the addition of rubber particles from recycled tyres", Construction and Building Materials, v. 35, pp. 633-641, oct, 2012.

[11] CAMÕES, A., CARDOSO, C., CUNHA, S. et al., "Caracterização de materiais compósitos à base de gesso FGD”, In: Anais do $8^{\circ}$ Congresso Nacional de Mecânica Experimental Guimarães, Universidade do Minho, abr, 2010.

[12] MAGALHÃES, A. C. T. V., ALMEIDA, J. G. "O uso da mucilagem de cacto em pastas de gesso: efeitos na absorção de água e na resistência à flexão estática”, Ambiente Construído, v. 10, n. 1, pp. 139-151, jan./mar. 2010. 
[13] OLIVEIRA, M P. de, BARBOSA, N. P., TORRES, S. M. et al., "Compósitos à base de gesso com resíduos de EVA e vermiculite”. Revista Brasileira de Engenharia Agrícola e Ambiental, v. 16, n. 6, pp. 684-689, Jun. 2012.

[14] SELAMAT, M. E., HASHIM, R., SULAIMAN, O. et al., "Comparative study of oil palm trunk and rice husk as fillers in gypsum composite for building material”, Construction and Building Materials, v. 197, p. 526+, Feb. 2019.

[15] PROTÁSIO, T. P., BUFALINO, L., GUIMARÃES JÚNIOR, M. et al., "Técnicas multivariadas aplicadas a avaliação de resíduos lignocelulosicos para a produção de bioenergia”, Ciência Florestal, v. 23, n. 4, pp. 771-781, 2013.

[16] EUROPEAN STANDARDS, “EN 13279-2: Gypsum binders and gypsum plasters, part 2: test methods”, Pilsen, 2006.

[17] ASSOCIAÇÃO BRASILEIRA DE NORMAS TÉCNICAS, "NBR 12127: Gesso para construção: determinação das propriedades físicas do pó: método de ensaio”, Rio de Janeiro, 1991.

[18] ASSOCIAÇÃO BRASILEIRA DE NORMAS TÉCNICAS, "NBR 13207: Gesso para construção civil: especificações", Rio de Janeiro, 1994.

[19] ASSOCIAÇÃO BRASILEIRA DE NORMAS TÉCNICAS, "NBR 7190: Projetos de estruturas de madeira”, Rio de janeiro, 1997.

[20] ASSOCIAÇÃO BRASILEIRA DE NORMAS TÉCNICAS, "NBR NM 45: Agregados - Determinação da massa unitária e do volume de vazios", Rio de Janeiro, 2006.

[21] ASSOCIAÇÃO BRASILEIRA DE NORMAS TÉCNICAS, "Dossiê Técnico Drywall - Chapas de Gesso, Convênio Sebrae ABNT - Chapas de gesso para drywall - Parte 2: Métodos de ensaio", 2010.

[22] PERES, L.; BENACHOUR, M.; SANTOS, V. A. O gesso: produção e utilização na construção civil. Recife: Bagaço, 2001.

[23] TETRAPAK, "Sustainability update 2014”, http://www.tetrapak.com/about/newsarchive/tetra-pak-releases-sustainability-update-2014, acessado em novembro de 2017.

[24] CHINTA, S. K., KATKAR, P. M., JAFER, M. M. "Natural fibres reinforced gypsum composites”, International Journal of Engineering and Management Sciences, v. 4, n. 3, pp. 318-325, 2013.

[25] RIVERO, A. J., GUZMÁN BÁEZ, A. de, NAVARRO, J. G. "New composite gypsum plaster-ground waste rubber coming from pipefoam insulation”, Construction and Building Materials, v. 55, pp. 146-152, 2014.

[26] HASELEIN, C. R., CALEGARI, L., ALBERTI, L. F. et al., "Fabricação de chapas de partículas aglomeradas usando gesso como material cimentante", Ciência Florestal, v. 12, n. 1, pp. 81-88, 2002.

[27] MARWARDT, L. J.; WILSON, T. R. C. Strength and related properties of woods grown in the United States, Technical Bulletin, 479, 67 p., 1935.

[28] NINDIYASARI, F. ZIMMERMANN, T., RANDOW, C. et al., "Characterization and mechanical properties investigation of the cellulose/gypsum composite", Journal of Composite Materials, v. 50, n. 5, pp. 657-672, 2016.

[29] VIVALDINI, D. O., MOURAO, A. A. C., SALVINI, V. R. et al., "Revisão: fundamentos e materiais para o projeto da microestrutura de isolantes térmicos refratários de alto desempenho", Cerâmica, v. 60, n. 354, pp. 297-309, 2014.

[30] GMOUH, A., EVE, S., SAMDI, A. et al. "Changes in plaster microstructure by pre-stressing or by adding gypsum grains: microstructural and mechanical investigations", Materials Science and Engineering, v. 352, pp. 325-332, 2003.

[31] MESQUiTA, R. G. A., MENDES, L. M., MENDES, R. F. et al. "Inclusão de feixes de sisal na produção de painéis MDP de eucalipto", Scientia Forestalis, v. 43, n. 105, pp. 75-82, mar. 2015.

\section{ORCID}

Luciana Silva Villela

Eliziane Denize de Castro

Laércio Mesquita Júnior

Maria Cecillia Ramos de Araújo Veloso

Rafael Farinassi Mendes

Lourival Marin Mendes

José Benedito Guimarães Júnior https://orcid.org/0000-0002-9246-9476 http://orcid.org/0000-0003-3456-3322

https://orcid.org/0000-0002-4122-1390 https://orcid.org/0000-0002-8053-180X https://orcid.org/0000-0002-1530-8388 https://orcid.org/0000-0001-8713-405X https://orcid.org/0000-0002-9066-1069 